\title{
ANALYSIS OF THE HOSPITALIZATION TIME IMPACT ON HOSPITAL MORTALITY FROM ACUTE MYOCARDIAL INFARCTION
}

\author{
Victor Zabashta \\ Center of Emergency Care and Disaster Medicine \\ 13 Nezalezhnosti ave., Kharkiv, Ukraine, 61058 \\ healthco@med.edu.ua \\ Bogdan Fedak \\ Department of Organization of health care, public administration ${ }^{1}$ \\ fbs58@ukr.net \\ Inna Lobova \\ Department of Organization of health care, public administration ${ }^{l}$ \\ inna.lobova2017@gmail.com \\ ${ }^{1}$ Kharkiv Medical Academy of Postgraduate Education \\ 13 Nezalezhnosti ave., Kharkiv, Ukraine, 61058
}

\begin{abstract}
Diseases of the circulatory system and their most severe form - acute myocardial infarction (AMI) - is one of the most important problems of modern medicine due to the steady increase in morbidity, negative impact on quality of life, early disability of patients. $19.5 \%$ of patients die from AMI, $50 \%$ among which die 90-120 minutes after the first symptoms of the disease.

The aim of the research was to analyse the impact of hospitalization on the mortality of patients with AMI and predict the risk of death in case of untimely hospitalization of this category of patients.

Materials and methods. We have conducted a retrospective analysis of 876 medical records of patients diagnosed with AMI who were treated in the cardiology department of Kharkiv Regional Clinical Hospital in 2019. During the study, we have used retrospective, logical, medical and statistical methods. Odds ratios and a $95 \%$ confidence interval were also calculated.

Results and discussion. The research revealed the impact of hospitalization on the organization of medical care and hospital mortality of patients with AMI. It was found that the largest share of patients with AMI, both among the dead and those who left the hospital, were hospitalized in the period from 2 to 12 hours from the onset of the disease ( $49.6 \%$ and $52.33 \%$, respectively), as well as in period after 24 hours $-28.00 \%$ and $21.70 \%$, respectively. The largest share of patients with AMI, regardless of the time of hospitalization were persons older than 60 years. The results of the analysis showed that in the period up to $2 \mathrm{~h}$ from the onset of the disease, the share of hospitalized patients with more severe heart muscle damage (presence of Q wave) was $91.35 \%$ against $8.65 \%$ of patients with AMI without ST segment elevation. It should be noted that in almost $50 \%$ of cases, patients with AMI without ST segment elevation were hospitalized after $24 \mathrm{~h}$ from the onset of the disease. At the same time, the largest share of deaths in this group of patients was observed in the hospital stay from 12 to 24 hours. According to the results of the research, risk factors for fatal outcome in AMI were identified, in particular male gender, the presence of an established ECG diagnosis of NSTEMI, conducting SKA in patients with AMI. It was also found that timely hospitalization of patients within the therapeutic window reduces the chances of hospital mortality by $52 \%$.

Conclusions. The obtained data indicate a strong relationship between the time of hospitalization and the organization of medical care and hospital mortality of patients with AMI. It is reliably established that timely hospitalization of patients within the therapeutic window reduces the chances of hospital mortality by $52 \%$ : HS is 0.483 (95\% CI $0.238-0.981), p=0.175$.
\end{abstract}

Keywords: acute myocardial infarction, risk factors, time of hospitalization, hospital mortality.

DOI: 10.21303/2504-5679.2021.001813

\section{Introduction}

Diseases of the circulatory system (DCS) and their most severe form - acute myocardial infarction (AMI) - is one of the most important problems of modern medicine due to the steady increase in morbidity, negative impact on quality of life, early disability of patients $[1,2]$ $19.5 \%$ of patients die from AMI, $20 \%$ of patients require constant third-party care and only $20-25 \%$ of people who have suffered a heart attack can return to work. At the same time, the fact 
that about $50 \%$ of patients die from a coronary attack in $90-120$ min after emergence of the first symptoms causes concern $[3,4]$.

The effectiveness of treatment of cardiovascular pathology also remains an acute problem. Despite the widespread introduction of thrombolysis and interventional treatments, mortality from AMI remains at a fairly high level, which determines the need for further search for effective ways to solve this problem $[5,6]$.

The development of a socially effective model to optimize the provision of emergency medical care to patients with AMI requires analysis not only of the modern treatment effectiveness and diagnostic strategies for the final results, but also the timeliness of such patients' hospitalization. In addition to surgical methods, the period of hospitalization from the onset of the disease plays an important role in the provision of medical care [7, 8].

The aim of the research was to analyze the impact of hospitalization on the mortality of patients with AMI and predict the risk of hospital mortality in case of late hospitalization of this category of patients.

\section{Materials and methods}

We have conducted a retrospective analysis of 876 medical records of patients diagnosed with AMI who were treated in the cardiology department of Kharkiv Regional Clinical Hospital in 2019. To collect the statistical material to determine risk factors, the method of copying medical history data was used. At the same time, we have calculated the odds ratio (VS) and $95 \%$ confidence interval (CI). In order to identify significant risk factors for early complications, a number of prognostic variables were considered, which are associated with the possibility of death in patients with AMI.

\section{Research results}

Recently, views on the strategy and tactics of treatment of patients with AMI have changed significantly. The result of the development of research in the field of cardiology was the opportunity to implement the concept of the «golden hour», which formed a new attitude to heart attack with its recognition as an emergency, the treatment of which requires emergency hospitalization, and medical care is provided in the first minutes in order to prevent the development or limit the size of myocardial necrosis. The therapeutic window for providing emergency care to a patient whose treatment effectiveness is limited is quite narrow, especially the first minutes and the first 2-3 hours after the onset of a heart attack. That is why the success of AMI treatment is largely determined by time $[9,10]$.

Considering the importance of the hospitalization time on the course of the disease and the development of complications, a research of hospitalization time impact on hospital mortality was conducted.

When analysing patients' medical records, they were divided into groups according to the time of hospitalization, based on the Unified Clinical Protocols for Medical Care of Patients with Acute Coronary Syndrome (ACS), according to which the patients must be hospitalized in a specialized hospital for 90-120 minutes [11]. Thus, the first group included persons who were hospitalized up to 2 hours after the onset of symptoms, the second - patients with a period of hospitalization from 2 hours to 12 hours, the third - from 12 to 24 hours and the fourth - after 24 hours (Table 1).

Table 1

Distribution of patients with AMI depending on the onset of symptoms before admission to hospital

\begin{tabular}{ccccc}
\hline \multirow{2}{*}{ Time of hospitalization } & \multicolumn{2}{c}{ Number of patients discharged from the hospital, \% } & \multicolumn{2}{c}{ Number of fatalities, \% } \\
\cline { 2 - 5 } & Men & Women & Men & Women \\
\hline Up to 2 hours & 9.99 & 3.86 & 5.60 & 1.60 \\
2 to 12 hours & 35.29 & 17.04 & 27.20 & 22.40 \\
12 to 24 hours & 7.86 & 4.26 & 13.60 & 6.40 \\
24 hours and more & 14.91 & 6.79 & & 100.00
\end{tabular}


As evidenced by the data in Table 1, the largest share of patients with AMI, both among the dead and those who left the hospital, were hospitalized in the period from 2 to 12 hours from the onset of the disease ( $49.6 \%$ and $52.33 \%$, respectively), as well as in the period after 24 hours $28.00 \%$ and $21.70 \%$, respectively. This fact indicates that this factor significantly affects hospital mortality.

The analysis of demographic indicators showed that men predominated in all groups, but the mortality rate was dominated by women $(14.40 \%)$ in the group of patients hospitalized after 24 hours.

No significant differences were found (Table 2) when comparing patients of different ages relative to the time of hospitalization.

Table 2

Structure of hospitalization time for inpatient treatment in different age groups

\begin{tabular}{ccccccc}
\hline \multirow{2}{*}{$\begin{array}{c}\text { Time of } \\
\text { hospitalization }\end{array}$} & \multicolumn{2}{c}{$\begin{array}{c}\text { Number of patients discharged from } \\
\text { the hospital, \% }\end{array}$} & \multicolumn{3}{c}{ Number of fatalities, \% } \\
\cline { 2 - 6 } & up to 44 years & $\mathbf{4 5 - 5 9}$ years & over 60 years & up to 44 years & $\mathbf{4 5 - 5 9}$ years & over 60 years \\
\hline Up to 2 hours & 15.79 & 15.81 & 12.85 & - & - & 8.04 \\
2 to 12 hours & 50.00 & 47.44 & 54.62 & - & 30.77 & 51.79 \\
12 to 24 hours & 13.16 & 11.63 & 12.25 & - & 7.69 & 16.07 \\
24 hours and more & 21.05 & 25.12 & 20.28 & - & 61.54 & 24.10 \\
Total & 100.00 & 100.00 & 100.00 & 100.00 & 100.00 & 100.00
\end{tabular}

As can be seen from Table 2, the largest share of patients with AMI who survived and who died, regardless of the time of hospitalization were persons older than 60 years.

In the first two hours after the onset of the disease, the patients of younger and middle age groups were equally frequently referred to a medical institution $(15.79 \%$ and $15.81 \%$, respectively). In the period from 2 to 12 hours, all age groups were hospitalized with a frequency of $47.44 \%$ in the group of patients aged $45-59$ years to $54.62 \%$ in the group of patients older than 60 years. At the same time, late treatment after 24 hours was detected in a quarter of patients in the middle age group.

The results of the analysis of the patient age structure indicate the absence of fatal AMI cases among people under the age of 44 , which, of course, is a positive medical and social trend.

It should be noted that the proportion of deceased patients who sought help after 24 hours from the onset of the disease was higher in the middle age group than among patients in the older age group.

According to the results of a comparative analysis of the myocardial damage depth and the timing of hospitalization of patients with heart attack, it was found that the share of hospitalized patients with more severe myocardial infarction (Q wave) was $91.35 \%$ against $8.65 \%$ of patients with AMI without elevation of the ST segment (Table 3) in the period up to 2 hours from the onset of the disease. A similar trend in the distribution of patients according to the established STEMI diagnosis was observed in the period from 2 to 12 hours and from 12 to 24 hours and was $90.84 \%$ vs. $9.16 \%$ and $83.52 \%$ vs. $16.48 \%$, respectively. It should be noted that in almost $50 \%$ of cases, patients with AMI without ST segment elevation were hospitalized after $24 \mathrm{~h}$ from the onset of the disease. At the same time, the largest share of deaths in this group of patients was observed in the hospital stay from 12 to 24 hours. The prevalence of deaths in patients with AMI without $\mathrm{Q}$ wave correlates with a later period of hospitalization of patients in this group compared with others.

It is known that after AMI therapy, it is extremely important to identify patients who are at high risk of further cardiac events, such as recurrent heart attack or death, in order to carry out timely intervention to prevent such events [12]. Therefore, the next stage of our research was to study the influence of factors that revealed heterogeneity in groups at different times of hos- 
pitalization (age of the patient, sex, place of residence, time of hospitalization since the onset of symptoms, ECG diagnosis, increased blood pressure in history) on the occurrence of early complications of AMI using two-dimensional analysis based on conjugation tables and calculations of the odds ratio (Table 4).

Table 3

Depth of myocardial damage in patients with AMI at different times of hospitalization

\begin{tabular}{|c|c|c|c|c|c|c|}
\hline \multirow{2}{*}{$\begin{array}{c}\text { Time of } \\
\text { hospitalization }\end{array}$} & \multicolumn{3}{|c|}{ Number of patients discharged from the hospital, $\%$} & \multicolumn{3}{|c|}{ Number of fatalities, $\%$} \\
\hline & $\begin{array}{l}\text { AMI with elevation } \\
\text { of ST segment }\end{array}$ & $\begin{array}{l}\text { AMI without ST } \\
\text { segment elevation }\end{array}$ & Total & $\begin{array}{l}\text { AMI with elevation } \\
\text { of ST segment }\end{array}$ & $\begin{array}{l}\text { AMI without ST } \\
\text { segment elevation }\end{array}$ & Total \\
\hline Up to 2 hours & 91.35 & 8.65 & 100.00 & 100.00 & - & 100.00 \\
\hline 2 to 12 hours & 90.84 & 9.16 & 100.00 & 98.39 & 1.61 & 100.00 \\
\hline 12 to 24 hours & 83.52 & 16.48 & 100.00 & 52.63 & 47.37 & 100.00 \\
\hline 24 hours and more & 50.31 & 49.69 & 100.00 & 82.86 & 17.14 & 100.00 \\
\hline
\end{tabular}

Table 4

Distribution of patients by risk factors according to hospital mortality

\begin{tabular}{|c|c|c|c|c|}
\hline Risk factors & $\begin{array}{l}\text { Patients with com- } \\
\text { plications Abs. (\%) } \\
\quad n=125(14.27)\end{array}$ & $\begin{array}{l}\text { Patients with im- } \\
\text { provement Abs. (\%) } \\
n=751(85.73)\end{array}$ & $\begin{array}{l}\text { Odds ratio } \\
\text { (CI } 95 \%)\end{array}$ & p-level \\
\hline Men & $69(55.2)$ & $511(68.04)$ & $0.579(0.394-0.850)$ & 0.114 \\
\hline $45-59$ & $13(10.4)$ & $215(28.63)$ & $0.289(0.159-0.525)$ & 0.088 \\
\hline Age over 60 years & $112(89.6)$ & $498(66.31)$ & $4.377(2.417-7.927)$ & 1.326 \\
\hline Place of residence: city & $83(66.4)$ & $490(65.25)$ & $1.053(0.705-1.571)$ & 0.215 \\
\hline Place of residence: village & $42(33.6)$ & $261(34.75)$ & $0.950(0.637-1.418)$ & 0.194 \\
\hline Time from onset of symptoms to EMD call (up to $2 \mathrm{~h}$ ) & $9(7.2)$ & $104(13.85)$ & $0.483(0.238-0.981)$ & 0.175 \\
\hline AMI with ST segment elevation & $109(87.2)$ & $610(81.23)$ & $1.575(0.903-2.745)$ & 0.447 \\
\hline AMI without ST segment elevation & $16(12.8)$ & $141(18.77)$ & $0.635(0.364-1.107)$ & 0.180 \\
\hline Hypertensive disease & $40(32.00)$ & $673(89.61)$ & 0.055 & 0.686 \\
\hline Conducted SKA & $53(42.40)$ & $596(79.23)$ & $0.191(0.129-0.285)$ & 0.039 \\
\hline Conducted conservative treatment & $60(48.00)$ & $130(17.31)$ & $4.409(2.960-6.569)$ & 0.897 \\
\hline
\end{tabular}

On the results of the analysis of the connection between the risk of death and gender, it was found that men have a $42 \%$ lower risk of hospital mortality (HS is 0.579 (95\% CI $0.394-0.850), p=0.114)$.

In patients aged $45-59$ years, the chances of complications are reduced by $71 \%$ (HS is 0.289 (95\% CI 0.159-0.525), $p=0.088$ ).

The study of the relationship between the risk of hospital mortality and place of residence (city, village) found that living in rural areas reduces the chances of death by $5 \%$ (HS is 0.950 (95\% CI 0.637-1.418), $p=0.194$ ).

Undoubtedly, the development of complications, in particular hospital mortality in patients with AMI, is influenced by the time of hospitalization of the patient from the moment of the disease, which, in its turn, is a recognized indicator of the quality of care [13, 14]. According to the results we found that hospitalization of patients for up to 2 hours reduces the chances of complications by $52 \%$ (HS is 0.483 (95\% CI $0.238-0.981), p=0.175)$.

According to the calculations, AMI without elevation of the ST segment reduces the risk of death by $36 \%$ (HS is equal to 0.635 (95\% CI 0.364-1.107) $p=0.180)$. 
It should be noted that the significant impact of such a co-existing disease as hypertension on the development of complications is not revealed.

It was also found that the survival of patients with AMI who underwent coronary artery stenting (CAS) was $81 \%$ higher than in patients receiving traditional drug therapy (HS is 0.191 (95\% CI 0.129-0.285), $p=0.039$ ).

\section{Discussion}

The results obtained in our study demonstrated the effect of the total time of hospitalization of patients on mortality in patients with AMI. This confirms the findings of a number of previous studies, in which the total time of myocardial ischemia was also an important predictor of death both in the hospital and in the long-term period $[15,16]$.

Thus, according to the Korean Register of AMI, in risk-adjusted groups, the total time of myocardial ischemia (less than $180 \mathrm{~min}$ ) remained the only independent predictor of a decrease in 30-day mortality (relative risk - RR 0.78 at $95 \%$ CI 0.62 to $0.99 ; p=0.04$ ) [17].

In a study by D. Kawecki et al. [18] described a paradox when a decrease in the total time of myocardial ischemia in the period from 2006 to 2013 did not affect the mortality rates at the population level. At the same time, at the individual level, an increase in the total time of myocardial ischemia remained an independent predictor of one-year mortality (RR 1.024, 95 \% CI from 1.015 to $1.034 ; p<0.001$ ).

In our study, a strong relationship between the time of hospitalization and the organization of medical care and hospital mortality of patients with AMI was found. Several previous studies have raised the question that the total time of myocardial ischemia is the best predictor of mortality and the development of major cardiac complications (MACE) compared with the «door-balloon» time $[19,20]$. At the same time, a reduction in the «door-to-balloon» time is associated with a decrease in mortality and MACE events with a short prehospital delay [21].

We have determined that age and female sex are factors associated with an increase in the total time of AMI. According to a study by Jr. J. R. Finnegan et al. [22], most women consider myocardial infarction a typical «male disease», which leads to an underestimation of personal risk and, as a consequence, late seeking medical care. In addition, women are often characterized by the presence of atypical clinical symptoms, which also complicates timely diagnosis and leads to an increase in the total time of AMI [23].

It was previously noted that in patients aged 45-59 years, the chances of complications are reduced by $71 \%$. In some cases, this is due to the complexity of timely diagnosis due to the frequent atypicality of symptoms in elderly patients [24].

However, despite the obvious advantages of reducing the total time of myocardial ischemia, the target recommendations for achieving this time interval are not clearly defined.

Study limitations. It should be noted that our work has a number of limitations. First of all, they are associated with the retrospective nature of the study and the inclusion of patient data in the analysis for a long period of time. In this regard, some relationships may be random.

Prospects for further research. Future work will focus on establishing the influence of additional factors in the untimely hospitalization of the patient using Cox regression.

\section{Conclusions}

The data obtained indicate a strong relationship between the time of hospitalization and the organization of medical care and hospital mortality of patients with AMI.

The research results identified risk factors for death with AMI. Thus, the factors that significantly increase the chances of hospital mortality in the study group of patients were:

- male gender, the odds ratio of which is 0.579 (95\% CI $0.394-0.850), p<0.114$;

- established ECG diagnosis of NSTEMI: HS =0.635 (95 \% CI 0.364-1.107), $p=0.180$;

- conducting SKA in patients with AMI: HS=0,191 (95\% CI 0.129-0.285), $p=0.039$.

It is reliably established that timely hospitalization of patients within the therapeutic window reduces the chances of hospital mortality by $52 \%$ : HS is 0.483 (95\% CI $0.238-0.981), p=0.175$. 


\section{Conflict of interests}

The authors declare that they have no conflicts of interest.

\section{Financing}

None.

\section{References}

[1] Terenda, N.O. (2015). Death rate from cardio-vascular diseases as a state problem. Bulletin of Scientific Research, 4, 11-13.

[2] Hruzeva, T. S., Haliienko, L. I., Dufinets, V. A. (2016). Medical and social aspects of the problem of non-infectious diseases as reflected by the world, European and national statistics. East European Journal of Public Health, 1 (26), 15-22.

[3] Anosova, E. V., Prashchayeu, K. I. (2011). The role of the ultrasound methods for the estimation of the biological age of human beings in the deteriorating environmental situation and the steady growth of morbidity and mortality from cardiovascular disease. Scien. J., 7, 238-242.

[4] Terenda, N. O. (2015) Prognostic estimation of incidence and prevalence of diseases of circulatory system. Bulletin of Social Hygiene and Health Protection Organization of Ukraine, 3 (65), 35-40. doi: http://doi.org/10.11603/1681-2786.2015.3.5763

[5] Tseluyko, V. I., Yarova, O. D. (2017). Long-term observation results of patients with atherosclerosis of the peripheral arteries of the lower extremities. Heart \& Vessels, 4, 39-47.

[6] Kuznetsov, V. A., Yaroslavskaya, E. I., Pushkarev, G. S., Zyryanov, I. P., Bessonov, I. S., Gorbatenko, E. A., Nyamtsu, A. M. (2014). Interrelation of transcutaneous coronary interventions for acute forms of coronary heart disease and mortality parameters in tyumen region inhabitants. Russian Journal of Cardiology, 6, 42-46. doi: http://doi.org/10.15829/1560-4071-2014-6-42-46

[7] Terenda, N. O. (2017). Impact of time of hospitalization of myocardial infarction patients on effectiveness of medical care. Bulletin of Scientific Research, 2, 60-63. doi: http://doi.org/10.11603/2415-8798.2017.2.7850

[8] Foo, C. Y., Bonsu, K. O., Nallamothu, B. K., Reid, C. M., Dhippayom, T., Reidpath, D. D., Chaiyakunapruk, N. (2018). Coronary intervention door-to-balloon time and outcomes in ST-elevation myocardial infarction: a meta-analysis. Heart, 104 (16), 1362-1369. doi: http://doi.org/10.1136/heartjnl-2017-312517

[9] Steg, Ph. G., James, S. K, Atar, D., Badano, L. P., Lundqvist, C. B., Borger, M. A. et. al. (2012). Task Force on the management of ST-segment elevation acute myocardial infarction of the Europe an Society of Cardiology (ESC). ESC Guidelines for the management of acutemyocardial infarction in patients presenting with ST-segment elevation. European Heart Journal, 33, 2569-2619. doi: http://doi.org/10.1093/eurheartj/ehs215

[10] Skybchyk, V. A. (2017). Modern approaches in management of patients with acute heart failure. Medicine of Ukraine, 3 (209), 13-19. doi: http://doi.org/10.37987/1997-9894.2017.3(209).222004

[11] Kravchenko, V. V., Khotina, S. H., Sokolov, M. Yu., Talaieva, T. V., Lishchyshyna, O. M., Amosova, K. M. et. al. (2016). Guidelines for the emergency, primary, secondary (specialized) and tertiary (highly specialized) medical care and medical rehabilitation «Acute coronary syndrome without ST segment elevation». Emergency medicine, 1 (72), 11-23.

[12] Song, P.-S., Jeong, M. H. (2019). Incidence, Predictors, and Implications of Re-Hospitalization for Heart Failure after Acute Myocardial Infarction. Journal of Cardiac Failure, 25 (8), S151. doi: http://doi.org/10.1016/j.cardfail.2019.07.435

[13] Lischyshyna, O. M., Stepanenko, A. V., Gorokh, Ye. L. (2010). Steps to development indicators of quality of medical care. Ukraine. Nation's Health, 4 (16), 85-91.

[14] Verulava, T., Maglakelidze, T., Jorbenadze, R. (2017). Hospitalization Timeliness of Patients with Myocardial Infarction. Eastern Journal Of Medicine, 22 (3), 103-109. doi: http://doi.org/10.5505/ejm.2017.36854

[15] Khalid, U., Jneid, H., Denktas, A. E. (2017). The relationship between total ischemic time and mortality in patients with STEMI: every second counts. Cardiovascular Diagnosis and Therapy, 7 (S2), S119-S124. doi: http://doi.org/10.21037/cdt.2017.05.10

[16] Chandrasekhar, J., Marley, P., Allada, C., McGill, D., O’Connor, S., Rahman, M. et. al. (2017). Symptom-to-Balloon Time is a Strong Predictor of Adverse Events Following Primary Percutaneous Coronary Intervention: Results From the Australian Capital Territory PCI Registry. Heart, Lung and Circulation, 26 (1), 41-48. doi: http://doi.org/10.1016/j.hlc.2016.05.114

[17] Kim, H. K., Jeong, M. H., Ahn, Y., Chae, S. C., Kim, Y. J., Hur, S. H. et. al. (2017). Relationship between time to treatment and mortality among patients undergoing primary percutaneous coronary intervention according to Korea Acute Myocardial Infarction Registry. Journal of Cardiology, 69 (1), 377-382. doi: http://doi.org/10.1016/j.jjcc.2016.09.002

[18] Kawecki, D., Morawiec, B., Gąsior, M., Wilczek, K., Nowalany-Kozielska, E., Gierlotka, M. (2019). Annual Trends in Total Ischemic Time and One-Year Fatalities: The Paradox of STEMI Network Performance Assessment. Journal of Clinical Medicine, 8 (1), 78. doi: http://doi.org/10.3390/jcm8010078

[19] Solhpour, A., Chang, K.-W., Arain, S. A., Balan, P., Loghin, C., McCarthy, J. J. et. al. (2015). Ischemic time is a better predictor than door-to-balloon time for mortality and infarct size in ST-elevation myocardial infarction: Ischemic Time Is 
Better Than Door to Balloon Time. Catheterization and Cardiovascular Interventions, 87 (7), 1194-1200. doi: http://doi.org/ 10.1002/ccd.26230

[20] Song, F., Yu, M., Yang, J., Xu, H., Zhao, Y., Li, W. et. al. (2016). Symptom-Onset-To-Balloon Time, ST-Segment Resolution and In-Hospital Mortality in Patients With ST-Segment Elevation Myocardial Infarction Undergoing Primary Percutaneous Coronary Intervention in China: From China Acute Myocardial Infarction Registry. The American Journal of Cardiology, 118 (9), 1334-1339. doi: http://doi.org/10.1016/j.amjcard.2016.07.058

[21] Denktas, A. E., Anderson, H. V., McCarthy, J., Smalling, R. W. (2011). Total Ischemic Time: the correct focus of attention for optimal ST-segment elevation myocardial infarction care. JACC: Cardiovascular Interventions, 4 (6), $599-604$. doi: http://doi.org/10.1016/j.jcin.2011.02.012

[22] Finnegan, J. R., Meischke, H., Zapka, J. G., Leviton, L., Meshack, A., Benjamin-Garner, R. et. al. (2000). Patient Delay in Seeking Care for Heart Attack Symptoms: Findings from Focus Groups Conducted in Five U.S. Regions. Preventive Medicine, 31 (3), 205-213. doi: http://doi.org/10.1006/pmed.2000.0702

[23] Sederholm Lawesson, S., Isaksson, R.-M., Thylén, I., Ericsson, M., Ängerud, K., Swahn, E. (2018). Gender differences in symptom presentation of ST-elevation myocardial infarction - An observational multicenter survey study. International Journal of Cardiology, 264, 7-11. doi: http://doi.org/10.1016/j.ijcard.2018.03.084

[24] Brieger, D., Eagle, K. A., Goodman, S. G., Steg, P. G., Budaj, A., White, K., Montalescot, G. (2004). Acute Coronary Syndromes Without Chest Pain, An Underdiagnosed and Undertreated High-Risk Group. Chest, 126 (2), $461-469$. doi: http://doi.org/10.1378/chest.126.2.461

Received date 30.04.2021

(C) The Author(s) 2021

Accepted date 20.05.2021

This is an open access article

Published date 25.05.2021

under the Creative Commons CC BY license

How to cite: Zabashta, V., Fedak, B, Lobova, I. (2021). Analysis of the hospitalization time impact on hospital mortality from acute myocardial infarction. EUREKA: Health Sciences, 3, 88-94. doi: http://doi.org/10.21303/2504-5679.2021.001813 